\title{
Atmospheric opacity estimation based on IWV derived from GNSS observations for VLBI applications
}

\author{
Grzegorz Nykiel $^{1}$ (D) Pawel Wolak $^{2} \cdot$ Mariusz Figurski $^{1}$
}

Received: 27 March 2017 / Accepted: 25 October 2017 / Published online: 6 November 2017

(C) The Author(s) 2017. This article is an open access publication

\begin{abstract}
Thermal emission of atmospheric water vapor has a great influence on the calibration of radio astronomical observations at millimeter wavelengths. The phenomenon of an atmospheric water vapor emits noise signal and attenuates astronomical emission. At $22 \mathrm{GHz}$, integrated water vapor (IWV) obtained from global navigation satellite systems (GNSS) is strictly related to atmospheric opacity $\left(\tau_{0}\right)$, which is a crucial parameter for data calibration. Therefore, providing highly precise and accurate IWV from GNSS measurements may be an alternative for microwave radiometers. Whereas it is not possible to estimate IWV directly from GNSS measurements, its value is strictly correlated with the zenith wet delay (ZWD) that is estimated together with the coordinates during the GNSS positioning. In this study, differential and Precise Point Positioning methods for ZWD estimation are tested using two different tropospheric mapping functions: Vienna mapping function (VMF) and global mapping function (GMF). After positioning, the IWV conversion is performed using meteorological parameters derived from a meteorological station located near a GNSS site. Analyses for a 3-month period from June 1 to August 30, 2016, were conducted. Based on these, we obtained a very high correlation between IWV and $\tau_{0}$ as measured by the Torun $32 \mathrm{~m}$ radio telescope, which amounts about 0.95 , for both PPP and differential solutions. Thus, techniques can be successfully used to estimate IWV and calculate $\tau_{0}$.
\end{abstract}

Grzegorz Nykiel

grzegorz.nykiel@pg.edu.pl

1 Faculty of Civil and Environmental Engineering, Gdansk University of Technology, G. Narutowicza 11/12, Gdańsk 80-233, Poland

2 Centre for Astronomy, Faculty of Physics, Astronomy and Informatics, Nicolaus Copernicus University, Grudziądzka 5, Toruń 87-100, Poland
However, the linear regression coefficients depend on the used positioning method.

Keywords GNSS $\cdot$ IWV $\cdot$ VLBI $\cdot$ Atmospheric opacity

\section{Introduction}

Since its beginning, global navigation satellite systems (GNSS) were mainly intended for the positioning, navigation and timing (PNT). Once the possibility of obtaining high accuracy using GNSS phase observations was recognized, scientists started to use it as a tool to measure the shape and size of the earth. Global and regional GNSS networks were established to define the global reference frame for scientific, educational and commercial applications. Examples of such networks are those of the International GNSS service (IGS) (Dow et al. 2009) or the EUREF permanent GNSS Network (EPN), which have been operating since 1994 and 1996, respectively. Owing to high accuracy and reliability, the GNSS data were used to define International Terrestrial Reference Frame (ITRF), including the latest release ITRF2014 (Altamimi et al. 2016).

The GNSS can also be used as a source of information on tropospheric and ionospheric parameters. In the ionosphere studies, the GNSS measurements are used to estimate global or regional maps of total electron content (TEC) (Hernández-Pajares et al. 2009), even in near real-time mode (Bergeot et al. 2014) and to monitor the traveling ionospheric disturbances (Nykiel et al. 2017). The GNSS signals are also useful to investigate the lower part of the atmosphere by estimating the precise tropospheric delay even in real-time mode ( $\mathrm{Li}$ et al. 2015). This parameter can be successfully used to investigate and monitor severe weather conditions (Guerova et al. 2016). Using the zenith total delay (ZTD) 
and meteorological parameters such as surface pressure and temperature, it is possible to estimate the integrated water vapor (IWV) (Bevis et al. 1992). This parameter plays a major role in shaping the dynamic processes in the atmosphere and of the hydrologic cycle. Using long-term observations, it is possible to study changes over time in the IWV (Nilsson and Elgered 2008) or ZTD (Baldysz et al. 2016).

Radio astronomical observations at a wavelength shorter than $3 \mathrm{~cm}$ are commonly affected by atmospheric emission and opacity; hence, the data should be corrected. The opacity, which is a measure of atmospheric attenuation $\tau$, is mainly related to the oxygen and water vapor content and also their temporal and spatial variability. The measured flux density of any radio source must be multiplied by a factor of $e^{\tau}$ to obtain its real above-atmosphere flux density. In the case of our location observations made with a radio telescope at $22.2 \mathrm{GHz}$ showed that $\tau$ in clear sky conditions ranges from about 0.04 in winter to 0.35 in summer, which means that the received signal is attenuated by 4 and $30 \%$ respectively. ZWD and IWV also estimate the atmospheric opacity and could be converted to $\tau$.

To estimate opacity, different methods and instruments are used, for example, microwave radiometers or radio telescopes. The first method depends on weather conditions which affect the radiometer altitude range and even in good conditions is often limited up to $10,000 \mathrm{~m}$ in zenith direction. Moreover, radiometers can be quite expensive. The second method is time consuming and awkward in practice. The solution of the problem could be the use of GNSS measurements, which are relatively cheap, the processing methods are known quite well, and it is possible to estimate parameters even in real time (Ahmed et al. 2016). As was mentioned above, using GNSS observations, it is possible to obtain IWV, which conveniently determines the quantity of atmospheric water vapor scaled by the density of water. Thus, this value should be highly correlated with the atmospheric opacity.

The relationship between IWV and $\tau$ has already been reported in the literature. Deuber et al. (2005) presented the correlation between IWV and atmospheric opacity based on the measurements of IWV from three different instruments, i.e. the all-sky multi wavelength radiometer (ASMUWARA), a tropospheric water vapor radiometer, and a GNSS receiver, and the atmospheric opacity from the ground-based radiometer MIAWARA. They showed very good correlation, of the IWV measured with the different instruments (correlation coefficient over 0.97). Moreover, the linear regression coefficients for the relation between MIAWARA opacity and IWV measured by other instruments were provided. They were 177.1574 and -3.5317 , for the $a$ and $b$ coefficients respectively, with the correlation value being 0.9489 . However, they did not provide any information about the GPS processing and how the IWV was obtained.
Based on the opacity measurements at $22 \mathrm{GHz}$ and the atmospheric transmission of microwave (ATM) model, Marvil (2010) presented a coefficient table of a linear relation between $\tau$ and IWV. He provides the values for the frequency range between 1 and $50 \mathrm{GHz}$ with $250 \mathrm{MHz}$ steps. Early the IWV values were calculated from the measurement of opacity at $22 \mathrm{GHz}$ and did not come from the GNSS processing. The coefficients of the linear regression amounted to 136.47 and -1.71 for $a$ and $b$, respectively. If we relate these values to those from Deuber et al. (2005), the noticeable difference for both coefficients is seen.

In this study, we present the correlation between IWV and the atmospheric opacity and the linear regression coefficients. We also focused on choosing an optimal positioning method in order to obtain the highest possible correlation between these parameters. Thus, we applied two commonly used processing strategies: Precise Point Positioning (PPP) and differential network positioning based on double differences (DD). To process GNSS observations, the Bernese GNSS Software Version 5.2 (rev. 2015-03-09) (Dach et al. 2015) was used. Each method was employed twice, with different a priori tropospheric delay models and mapping functions. In both cases, two mapping functions were used: the Vienna mapping function 1 (VMF1) (Boehm et al. 2006a) with atmospheric pressure loading (APL) (Wijaya et al. 2013) and the global mapping function (GMF) (Boehm et al. 2006b) with no APL applied. Additionally, for the conversion of the ZWD values into IWV and for estimate the opacity, two different water vapor weighted mean temperature models were used. The first one was proposed by Bevis et al. (1992) and is commonly used in the GNSS processing. It is based on a linear regression between surface temperature and weighted mean temperature. The second one was presented by Maddalena and Johnson (2005) and is also based on a similar linear regression, but additionally, some dependency on the frequency of the signal was included. Besides the IWV values, we also used the atmospheric opacity $(\tau)$ data obtained with the Torun $32 \mathrm{~m}$ radio telescope using the sky-dip method. The measurements of IWV were then compared to the opacity values, and the correlation together with the linear coefficients was determined. In the end, we propose an optimal method of IWV estimation which gives the best correlation with atmospheric opacity.

\section{Methodology}

The amount of the water vapor content in the troposphere can be measured by means of, e.g., radiometers or radiosondes. However, for this purpose also space geodetic techniques such as very long-baseline interferometry (VLBI), Doppler orbitography and radiopositioning integrated by satellite (DORIS) or GNSS, can be used. We present the 
methodology of estimating the amount of water vapor content from GNSS observations, which can be expressed by the IWV parameter. To calculate its value, we use two different water vapor weighted mean temperatures, for which a description and comparison is presented in this section. Moreover, we provide a description of the sky-dip method, which we used to estimate atmospheric opacity from the measurements at $22 \mathrm{GHz}$ derived from $32 \mathrm{~m}$ radio telescope.

\section{Atmospheric opacity: $\tau_{0}$}

In addition to the radiation attenuation coming from cosmic radio sources, the Earth atmosphere also emits noise. Therefore, the atmospheric opacity must be known and taken into account in order to obtain the intrinsic flux density of a studied radio source. Highly variable water vapor emissions depending on the weather conditions affect observations at millimeter wavelengths, especially in the $22 \mathrm{GHz}$ band.

In this study, the atmospheric opacity in the zenith $\tau_{0}$ was measured using the so-called sky-dip method. During this procedure, the antenna scans the sky from the zenith to the horizon at a fixed azimuth. The K-band (21-25 GHz) receiver of the Torun $32 \mathrm{~m}$ radio telescope was used.

Power received from the sky at different zenith distances $P_{\text {sky }}(z)$ was compared to the power emitted by absorbing material $P_{\text {load }}$, at known temperature $T_{\text {load }}$. Before any skydip started, the receiver was automatically shielded (for a moment) by the load, and then a power of its signal was measured in order to make the comparison. The power $P_{\text {sky }}(z)$ measured on the sky by the receiver with the noise temperature $T_{\text {rec }}$ at zenith distance $z$ can be expressed as follows:

$P_{\text {sky }}(z)=G\left[T_{\text {rec }}+\left(1-e^{-\tau_{0} \sec (z)}\right) T_{\mathrm{m}}\right]$

where $G$ is the receiver gain assumed to be constant, and $T_{\mathrm{m}}$ is the mean temperature of the atmosphere. The much less significant contribution of signals from cosmic microwave background radiation and antenna spillover were neglected for simplicity (White and Zauderer 2009).

The power measured on the load is calculated using the formula:

$P_{\text {load }}=G\left[T_{\text {rec }}+T_{\text {load }}\right]$

To determine $\tau_{0}$ and $T_{\text {rec }}$, it is sufficient to measure the power ratio to the measurements:

$Y(z)=\frac{P_{\text {load }}}{P_{\text {sky }}(z)}=\frac{\frac{T_{\text {rec }}}{T_{\mathrm{m}}}+\frac{T_{\text {load }}}{T_{\mathrm{m}}}}{\frac{T_{\text {rec }}}{T_{\mathrm{m}}}+\left(1-e^{-\tau_{0} \sec (z)}\right)}$

A couple of exemplary sky-dips $Y(\sec (z))$ which were taken at very different weather conditions are presented in Fig. 1. It is clear that the $Y(\sec (z))$ values strongly depend on the

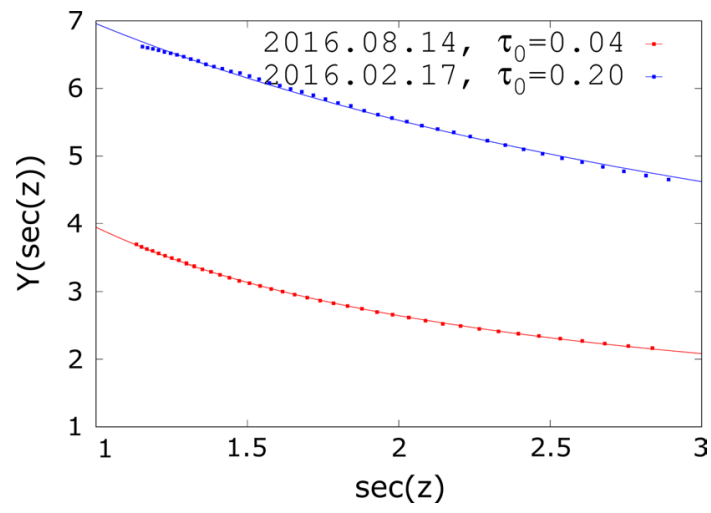

Fig. 1 Exemplary sky-dips realized in radically different (red-summer/blue-winter) weather conditions

season. During the winter, the values are almost two times larger than in the summer, which is caused by the lower amount of water vapor in cold air and results in a decrease in the sky brightness temperatures and $P_{\text {sky. }}$.

The Torun $32 \mathrm{~m}$ radio telescope used in our study is a fully steerable antenna with a horizontal mount which works in classical Cassegrain mode in which the feed antenna is mounted at the bottom of the concave main parabolic reflector (dish) in its optical axis and is illuminated by convex (hyperbolic) secondary reflector suspended in front of the dish. Since its commission, the antenna regularly participates in VLBI and e-VLBI experiments. Currently, the available receiving systems covers following frequency bands: 1.2-1.7, 4-8, 21-25, 27-33 GHz.

\section{Integrated water vapor: IWV}

IWV cannot be obtained directly from the GNSS observations, but it can be easily calculated from tropospheric delay (ZTD), which is one of the parameters estimated during precise positioning. The ZTD can be represented as the sum of hydrostatic and wet atmospheric delays (ZHD and ZWD, respectively):

$\mathrm{ZTD}=\mathrm{ZHD}+\mathrm{ZWD}$

ZHD can be calculated using the Saastamoinen model with meteorological parameters (Saastamoinen 1972):

$$
\begin{aligned}
\mathrm{ZHD}= & \left(2.2768 * 10^{-3}\right) P_{\mathrm{S}} /\left[1-2.66 * 10^{-3} * \cos (2 \varphi)\right. \\
& \left.-2.8 * 10^{-7} \mathrm{H}\right]
\end{aligned}
$$

In (5), the $P_{\mathrm{S}}$ denotes the surface pressure (expressed in $\mathrm{hPa}$ ) at the height of the GNSS antenna ( $H$ in meters), and $\varphi$ is the latitude of the receiver.

If the ZHD value is calculated from (5) and ZTD is obtained from the GNSS processing, the ZWD can be easily calculated by subtracting the ZHD from the ZTD. Then, its value can be used to calculate the IWV value. The ZWD 
is related to IWV via factor $\kappa$ (Askne and Nordius 1987) in the form:

$\mathrm{IWV}=\kappa \mathrm{ZWD}$

where $\kappa$ is defined as:

$\kappa=\left[10^{-6}\left(k_{3} / T_{\mathrm{m}}+k_{2}^{\prime}\right) R_{v} \rho\right]^{-1}$

and $T_{\mathrm{m}}(K)$ is the water vapor weighted mean temperature (mean temperature of the column of water vapor above the receiver $), k_{2}^{\prime}=(17 \pm 10) \mathrm{K}^{2} \mathrm{mbar}^{-1}$, $k_{3}=(3.776 \pm 0.004) 10^{5} \mathrm{~K}^{2} \mathrm{mbar}^{-1}, \rho$ is the density of water, and $R_{v}$ is the gas constant for the water vapor.

To estimate the tropospheric delay from GNSS, we used the PPP and the DD methods. Their parameters are given in Table 1. Two troposphere models were used and their impact on both IWV and correlation with the $\tau_{0}$ parameter were investigated. In the first one, VMF1 (Boehm et al. 2006a) was used as a source for an a priori tropospheric delay value together with the wet mapping function. This model is generated using data from ECMWF (European Centre for Medium-Range Weather Forecasts) for a $2^{\circ} \times 2.5^{\circ}$ grid, with a 6 -h time resolution $(0,6,12,18$ UTC). It contains information (for each point in grid) about values of the coefficients which are necessary to calculate the mapping functions. Moreover, the grid files include also the a priori zenith delay for the hydrostatic and wet part of the troposphere. Boehm et al. (2006b) proposed also the empirical model called GMF, which was used in our second solution. The GMF has a similar form to the VMF1. The coefficients of this mapping function were determined using monthly profiles of temperature, pressure and humidity for the grid of $15^{\circ} \times 15^{\circ}$ from the ERA-40 data for the period September 1999 to August 2002. The advantage of GMF is that it is not necessary to update the information about the function coefficients or a priori delays. They are determined on the basis of polynomial coefficients included in GMF. However, this is reflected in the mapping function and the accuracy of the a priori tropospheric delay values. More accurate are the parameters from VMF1, which are determined on the basis of an operational numerical weather model. In our study, both VMF1 and GMF were used in PPP and DD processing and their results are analyzed below. As was suggested by Steigenberger et al. (2009) together with VMF1, we applied atmospheric pressure loadings (APL).

In our study, we used 30-s interval GPS + GLONASS observations from June 1 to August 30, 2016, from station PIWN. The receiver type was TOPCON NET-G3A with antenna TPSCR.G5 TPSH. The station is located $250 \mathrm{~m}$ from the radio telescope (Fig. 2). This station is included in the private TPI NETpro network, which consists of 136 reference stations spread evenly across Poland. This is a nationwide system owned by TPI Poland company providing differential corrections for GNSS (GPS + GLONASS) measurements. It is also adapted to operate with the European system Galileo. The stability of TPI NETpro stations is monitored in the same way as the national ASG-EUPOS and the EPN networks (Figurski et al. 2015). TPI NETpro is part of the global network TopNET Live established by the Topcon company. Figure 2 shows the location of TPI NETpro

Table 1 GNSS processing parameters for PPP and DD solutions

\begin{tabular}{ll}
\hline & DD \\
\hline Satellite systems & GPS/GLONASS \\
Input data & Daily RINEX 2.11 \\
Observation interval & 30 -s interval \\
Period & 1 st June-30th August 2016 \\
Observation cut-off angle & $3^{\circ}$ \\
Orbits, EOP, clock & Precise satellite clock, orbits, and EOP from CODE \\
GPS phase ambiguity handling & Estimation dependent on baseline length (L6/L3, L1/L2, L5/L3 with \\
& SIGMA strategy, L1/L2 with QIF strategy) (Dach et al. 2015) \\
Ionosphere handling & Global model (CODE) for HOI L3 \\
Troposphere handling & Solution 1 \\
& A priori model: VMF1; \\
& Mapping function WET VMF1; \\
& CHENHER gradients model (Chen and Herring 1997) \\
& Solution 2 \\
& A priori model: GMF; \\
& Mapping function WET GMF; \\
Interval of troposphere parameter estimation & CHENHER Gradients model \\
Relative troposphere parameter constraining & 60 min \\
& ZTD 2 mm \\
& Gradients 0.2 mm
\end{tabular}




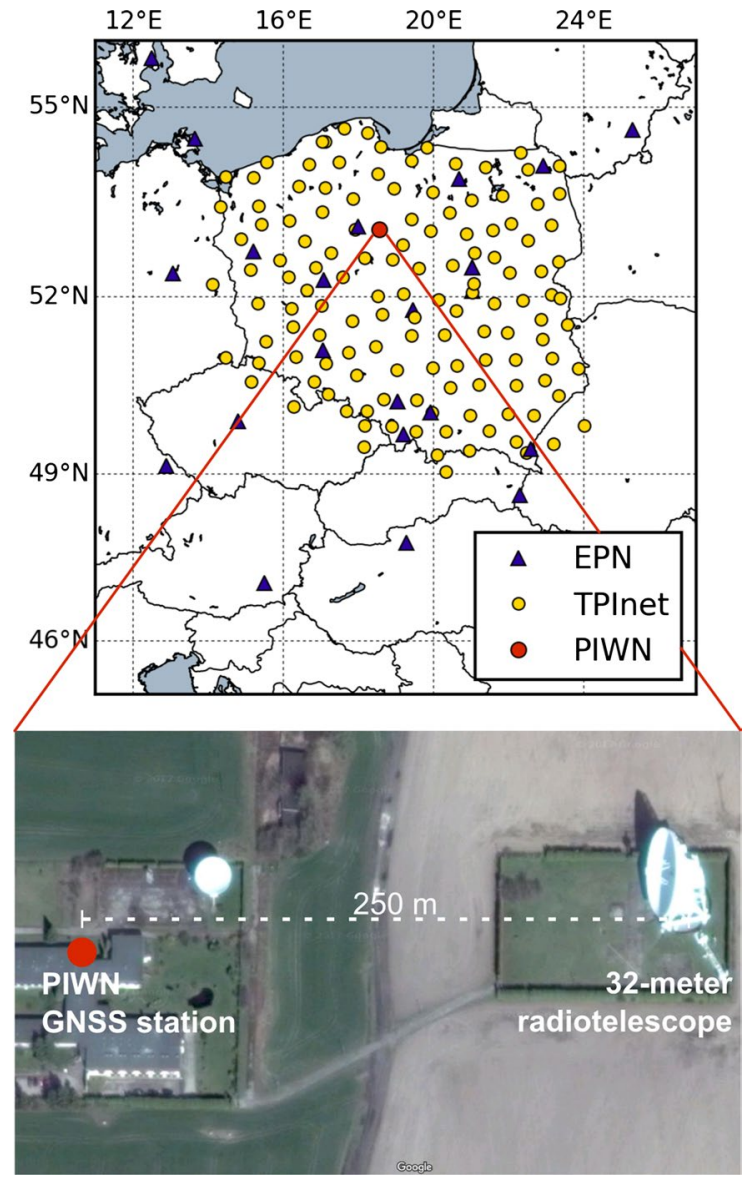

Fig. 2 Map of TPI NETpro network (yellow circles) with marked EPN stations (blue triangles) and location of PIWN GNSS station (red circle) and radio telescope from which observations were used in this study

stations (yellow circles), for which we estimated position and tropospheric parameters using both DD and PPP strategies. Our calculations were performed using the Bernese GNSS Software Version 5.2 (rev. 2015-03-09) (Dach et al. 2015). In case of the DD solutions, 21 fixed EPN stations were used, marked in Fig. 2 by a blue triangle, and minimum constraints were applied to define the geodetic datum.

The meteorological sensors providing the data used to calculate the ZHD values according to (5) are located near the station, at the height of the GNSS antenna.

\section{Water vapor weighted mean temperature: $T_{\mathrm{m}}$}

As we have mentioned above, the water vapor weighted mean temperature $\left(T_{\mathrm{m}}\right)$ is a necessary parameter to estimate both the IWV value from GNSS observations and $\tau_{0}$ using the sky-dip method. If we assume that the atmosphere is represented by $N$ layers, then $T_{\mathrm{m}}$ can be defined as a function of atmospheric temperature and humidity vertical profiles and approximated as (Davis et al. 1985):

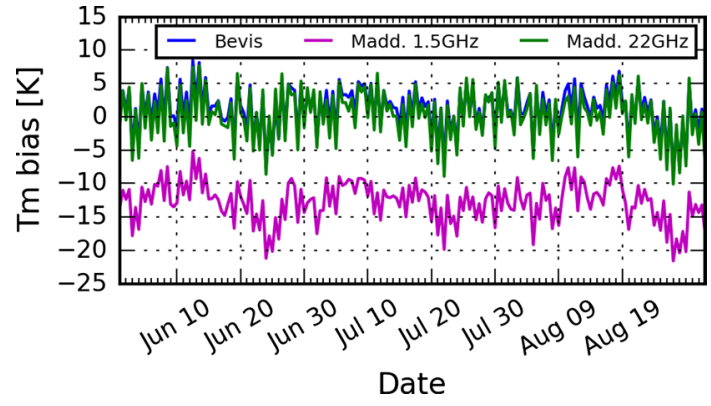

Fig. 3 Differences between $T_{\mathrm{m}}$ derived from radio soundings and calculated using different formulas: Bevis (blue line), Maddalena for $22 \mathrm{GHz}$ (green) and Maddalena for $1.5 \mathrm{GHz}$ (magenta)

$T_{\mathrm{m}} \equiv \frac{\int \frac{P_{v}}{T} \mathrm{~d} z}{\int \frac{P_{v}}{T^{2}} \mathrm{~d} z} \approx \frac{\sum_{i=1}^{N} \frac{P_{v}}{T} \Delta z_{i}}{\sum_{i=1}^{N} \frac{P_{v}}{T^{2}} \Delta z_{i}}$

where $P_{v}$ is the partial pressure (hPa) of water vapor and $T$ is the atmospheric air temperature (K).Equation (8) implies that to estimate $T_{\mathrm{m}}$ it is necessary to have profiles of meteorological parameters derived either from radio soundings observations or from numerical weather model. Bevis et al. (1992) suggested that $T_{\mathrm{m}}$ can be obtained from the surface air temperature $\left(T_{s}\right)$ :

$T_{m}=0.72 * T_{s}+70.2$

Several authors have attempted to retrieve this relation based on global (Mendes 2000; Schuler 2001) and local scales [Solbrig 2000 (Germany); Suresh et al. 2007 (India) or Song and Grejner-Brzezinska 2009 (Korea)]. In most recent publications (Van Malderen et al. 2014) related to calculating IWV from GNSS measurements, the Bevis formula was still the most popular. In VLBI measurements, the common method used to estimate weighted mean temperature was presented by Maddalena and Johnson (2005) and it also depends on the frequency $(f)$ of the signal:

$T_{\mathrm{m}}=A+B *\left(T_{s}-273.15\right)$

where

$A=259.691860-1.66599001 * f+0.226962192 * f * 2$.

$-0.0100909636 * f * 3 .+0.00018402955 * f * 4$.

$-0.00000119516 * f * 5$.

$B=0.42557717+0.03393248 * f$

$+0.000257983 * f * 2 .-0.0000653903 * f * 3$.

$+0.00000157104 * f * 4 .-0.00000001182 * f * 5$.

$f$ is the frequency in $\mathrm{GHz}$.

Since we use the data from GNSS and radio telescope measurements, we applied both (9) and (10). Figure 3 shows the comparison of $T_{\mathrm{m}}$ obtained with the two methods. $T_{\mathrm{m}}$ derived from the meteorological radio sounding observations are used as a reference. A large shift $(-12.8 \mathrm{~K})$ for $T_{\mathrm{m}}$ determined using the Maddalena formula (10) for signals 
with a $1.5 \mathrm{GHz}$ frequency (which approximately corresponds to the GNSS signal frequencies), can be seen. The same formula for $22 \mathrm{GHz}$ gives similar results to that from the Bevis formula, $-0.2 \pm 3.9$ and $1.1 \pm 3.3 \mathrm{~K}$, respectively. Using the Maddalena and Johnson formula for the GNSS frequencies, we obtained shifts in the IWV results, which are presented in the following below.

\section{Results}

Here, we present the comprehensive results of our analysis. First, differences between atmospheric opacities obtained using different $T_{\mathrm{m}}$ are presented. Second, a comparison between ZWD derived from GNSS positioning using VMF1 and GMF is shown. Based on the obtained ZWD solutions, the ZWD to IWV conversion was made. Thus, we present an impact analysis of different mapping functions on this parameter. An IWV bias caused by the water vapor weighted mean temperature is shown as well. At the end, the correlation between IWV and $\tau_{0}$ are presented for both PPP and DD processing strategies, with VMF1 and GMF applied.

\section{Atmospheric opacity differences}

In our research, we use the two different methods to estimate both the IWV and $\tau_{0}$ values. Thus, in this section, the $\tau_{0}$ differences caused by these methods are presented. The bias values are shown in Fig. 4. There are no significant differences between the atmospheric opacity estimated using $T_{\mathrm{m}}$ calculated with the Bevis and the Maddalena formulas, except for the June 25 where the maximum value occurred with -0.0035 . The mean bias for the whole period is close to zero. We conclude that the water vapor weighted mean temperature has no significant effect on $\tau_{0}$ estimation.

\section{ZWD values and IWV differences}

In the DD and PPP processing strategies, we applied both the VMF1 and GMF. In Fig. 5, the differences between ZWD,

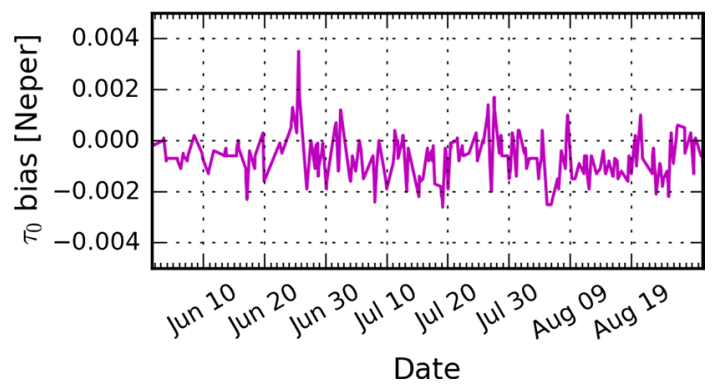

Fig. 4 Bias of the atmospheric opacity $\left(\tau_{0}\right)$ estimated using Bevis and Maddalena formulas

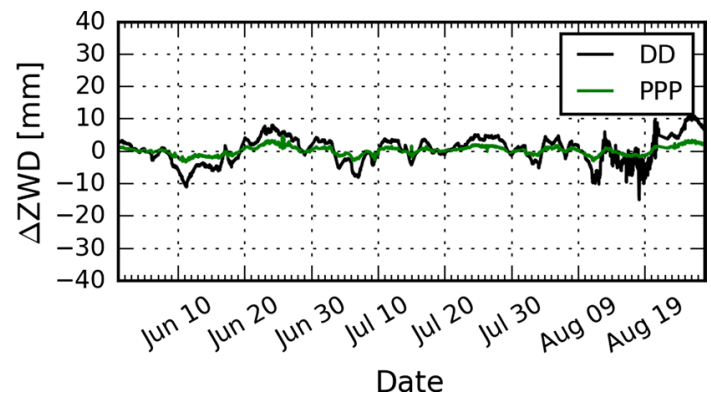

Fig. 5 Differences between ZWD estimated with the VMF1 and GMF using DD (black) and PPP (green) solutions

estimated with VMF1 and GMF using the DD (black line) and PPP (green line) strategies, are shown. It is clearly visible that the largest differences occurred for the DD method, for which the mean bias amounted to $0.38 \pm 4.12 \mathrm{~mm}$. In selected epochs, the differences reached up to $10 \mathrm{~mm}$. Better consistency was obtained for PPP processing, where mean bias between the VMF1 and GMF reached up to $0.17 \mathrm{~mm}$, with a standard deviation of $1.29 \mathrm{~mm}$.

In Fig. 6, the ZWD bias between PPP and DD is presented. The best agreement is for VMF1 with an average difference of $1.40 \pm 5.97 \mathrm{~mm}$. The results for GMF turned out to be much worse because of the higher average bias value $(1.62 \pm 6.98 \mathrm{~mm})$ and the occurrence of oscillations. These oscillations also translate into differences in the IWV (Fig. 7), causing a bias between PPP and DD at the level of $0.25 \pm 1.10 \mathrm{~mm}$. The average bias is $0.22 \pm 0.95 \mathrm{~mm}$ when using VMF1. If we look at the mean value of absolute IWV differences, the results are even more in favor of VMF1,
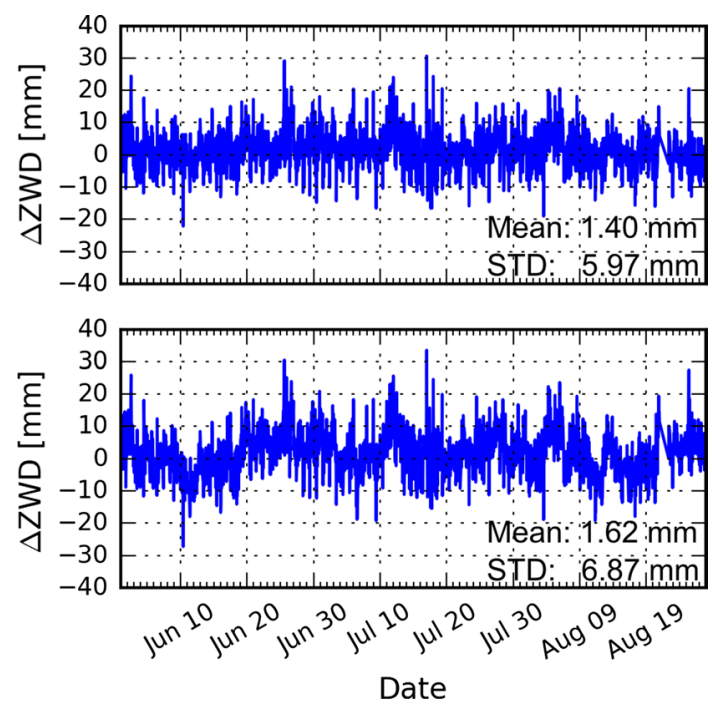

Fig. 6 Differences between ZWD calculated using PPP and DD solutions with VMF1 (top) and GMF (bottom) 

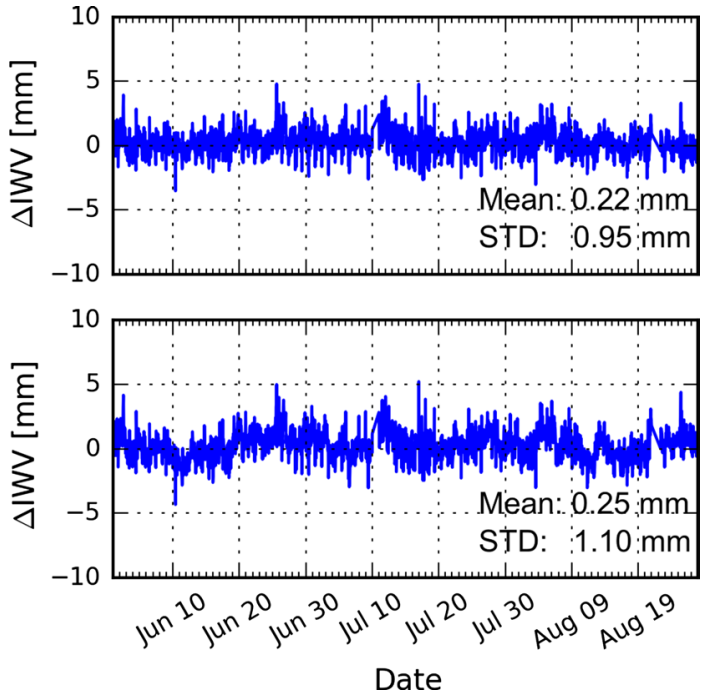

Fig. 7 Differences between IWV calculated using PPP and DD solutions with VMF1 (top) and GMF (bottom) because they amounted to $0.74 \mathrm{~mm}$ for VMF1 and $0.88 \mathrm{~mm}$ for GMF. We conclude that greater compatibility in the solutions is obtained with VMF1.

\section{Correlation between IWV and $\tau_{0}$}

Figure 8 shows the correlation between IWV derived from GNSS processing and $\tau_{0}$ estimated from the sky-dip method. It can be approximated by:

$\mathrm{IWV}=a * \tau_{0}+b$

where $a$ and $b$ are the slope and intercept of the fitted line, respectively.

Figure 8 (top) represents the correlation between IWV and $\tau_{0}$, which are determined using $T_{\mathrm{m}}$ obtained from the Bevis formula. In the bottom row, the IWV values were estimated using Bevis method, but the $\tau_{0}$ were calculated using the Maddalena method. We decided to show such a comparison to check how the usage of different mean temperature values impacted on the correlation parameters. Nevertheless, we did not use Maddalena mean temperature
Fig. 8 Correlation between IWV and $\tau_{0}$ derived from GNSS processing using GMF
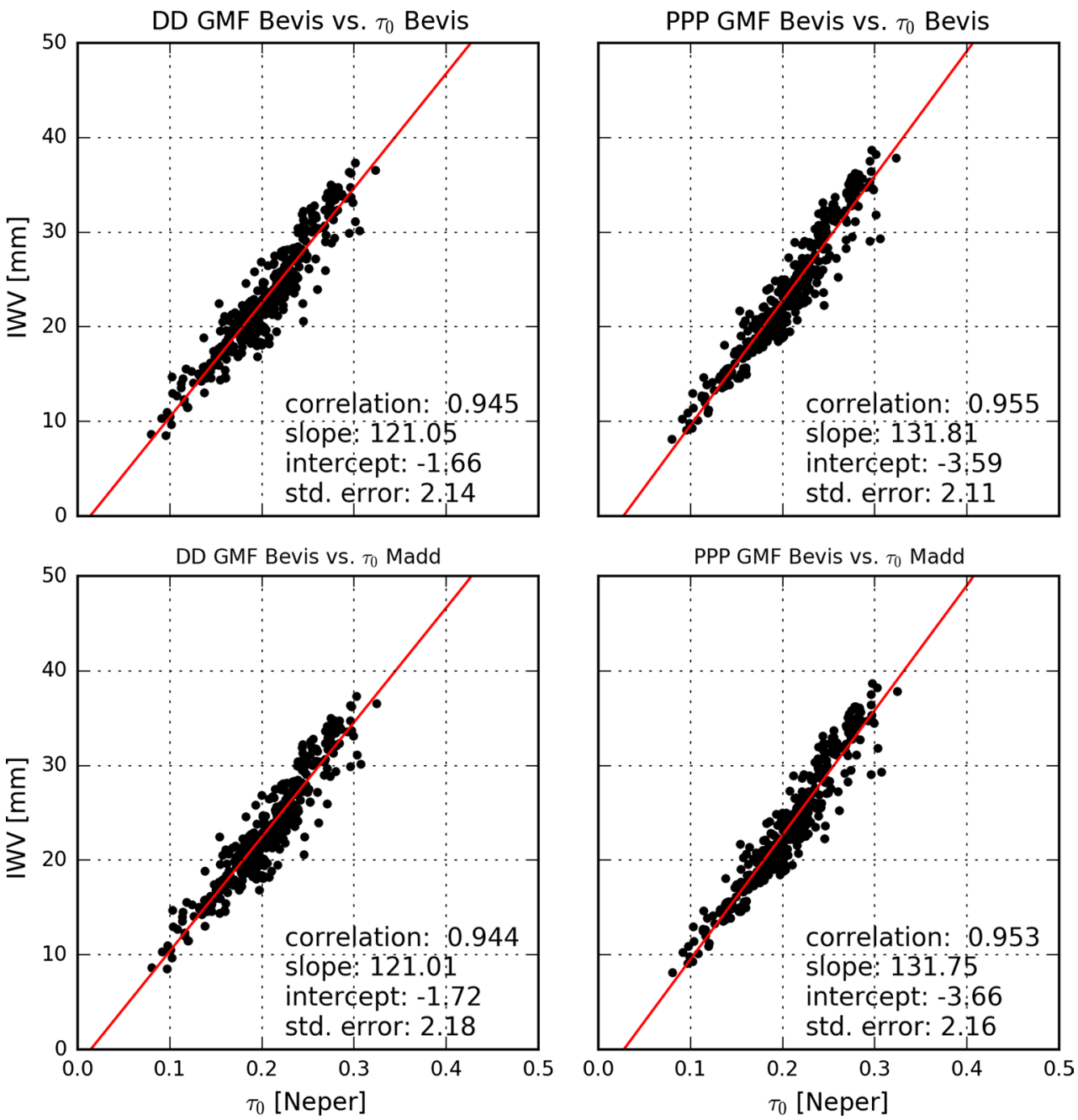


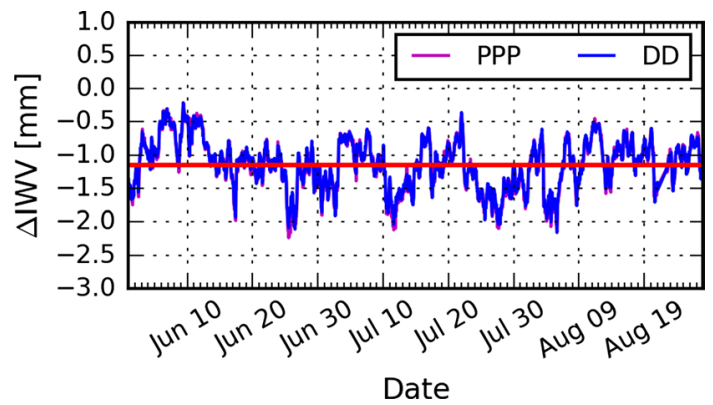

Fig. 9 Differences between IWV calculated using Bevis and Maddalena weighted mean temperature. PPP VMF1 solutionmagenta line; DD VMF1 solution-blue line

for the conversion from ZWD to IWV, because its causes at $1.5 \mathrm{GHz}$ frequency the systematic bias for both $T_{\mathrm{m}}$ (Fig. 3) and IWV values (Fig. 9).

From Fig. 8, we notice that the correlation is consistently high with values between 0.944 and 0.955 . The values of the correlation coefficients are very similar to
0.9489 reported by the Deuber et al. (2005). The best correlation value was obtained for the PPP solution with GMF and with the Bevis et al. (1992) formula to estimate the $T_{\mathrm{m}}$ values. This solution is also characterized by the lowest standard error of 2.11. Furthermore, some differences are visible between PPP and DD solution for the linear regression coefficients.

Figure 10 presents the correlation for the solutions for which VMF was used. The best solution was obtained for the DD processing strategy, where the standard error amounted to 2.00. This value is the lowest for all solutions. The second lowest value was also obtained for the DD solution, but in this case, different methods for the mean temperature calculation were used. For DD VMF Bevis versus $\tau_{0}$ Madd. solution we obtained standard error amounting 2.05. The correlation values for all VMF1 solutions are very similar and are higher than in case of the GMF solutions. Similarly, as in the previous results, also in this case the difference between the linear regression coefficient can be observed, but the differences between them are smaller.
Fig. 10 Correlation between IWV and $\tau_{0}$ derived from GNSS processing using VMF1
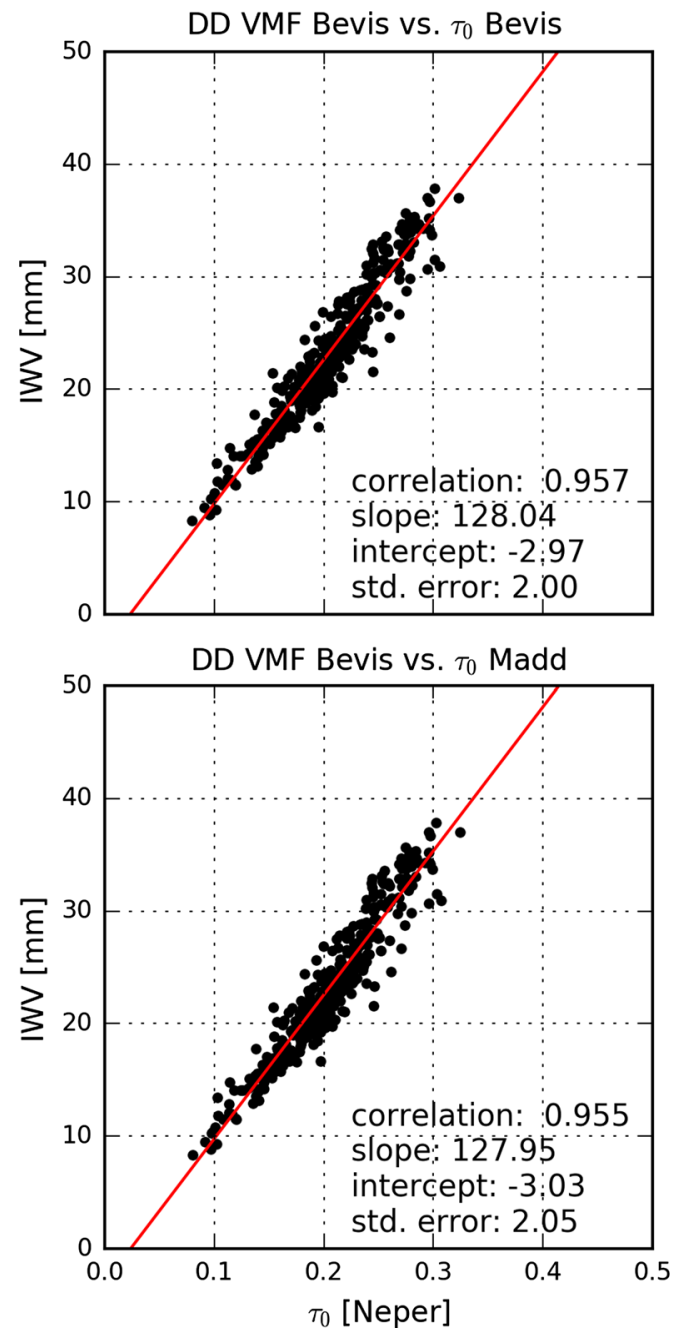

PPP VMF Bevis vs. $\tau_{0}$ Bevis

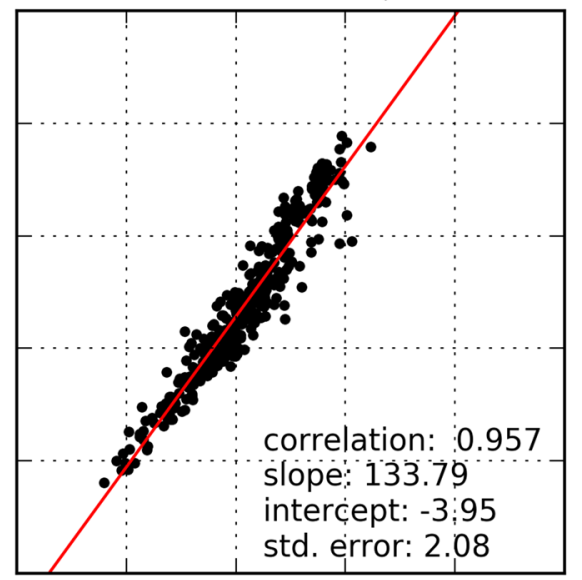

PPP VMF Bevis vs. $\tau_{0}$ Madd

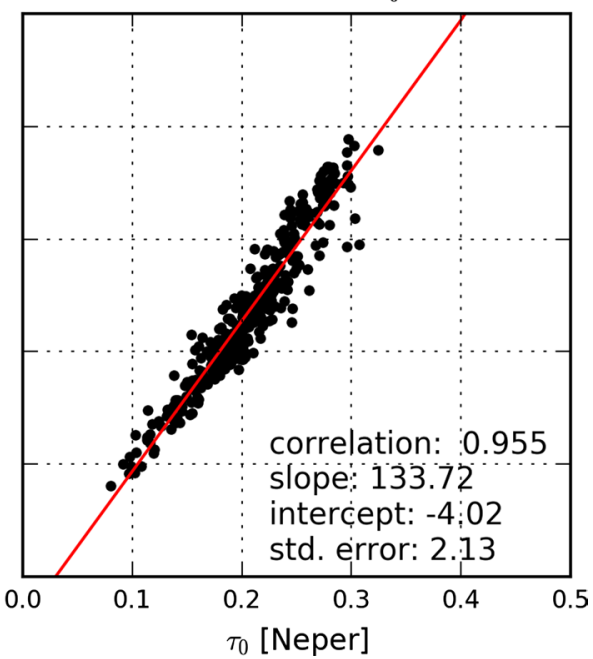


Table 2 Correlation $(r)$ and linear regression coefficients with standard error between IWV and $\tau_{0}$ for all tested solutions

\begin{tabular}{llllll}
\hline Solution & $r$ & $a$ & $b$ & SE \\
\hline $\begin{array}{l}\text { DD GMF Bevis versus } \tau_{0} \\
\text { Bevis }\end{array}$ & 0.9455 & 121.0543 & -1.6554 & 2.1449 \\
DD GMF Bevis versus $\tau_{0}$ & 0.9438 & 121.0078 & -1.7241 & 2.1798 \\
$\quad$ Madd. & & & & \\
DD VMF Bevis versus $\tau_{0}$ & $\mathbf{0 . 9 5 6 8}$ & $\mathbf{1 2 8 . 0 4 1 7}$ & $\mathbf{- 2 . 9 6 8 4}$ & $\mathbf{2 . 0 0 1 7}$ \\
$\quad$ Bevis & & & & \\
$\begin{array}{l}\text { DD VMF Bevis versus } \tau_{0} \\
\text { Madd }\end{array}$ & 0.9547 & 127.9466 & -3.0315 & 2.0503 \\
PPP GMF Bevis versus $\tau_{0}$ & 0.9547 & 131.8101 & -3.5878 & 2.1136 \\
$\quad$ Bevis & & & & \\
PPP GMF Bevis versus $\tau_{0}$ & 0.9529 & 131.7482 & -3.6603 & 2.1566 \\
$\quad$ Madd. & & & & \\
$\begin{array}{l}\text { PPP VMF Bevis versus } \tau_{0} \\
\text { Bevis }\end{array}$ & 0.9573 & 133.7948 & -3.9483 & 2.0778 \\
PPP VMF Bevis versus $\tau_{0}$ & 0.9554 & 133.7174 & -4.0189 & 2.1251 \\
$\quad$ Madd & & & & & \\
Deuber et al. (2005) & 0.9489 & 177.5423 & -3.0379 & - \\
Marvil (2010) & - & 136.47 & -1.71 & - \\
\hline
\end{tabular}

The best DD and PPP solutions are highlighted in bold (DD) and italics (PPP)

Table 2 presents the detailed statistics for all solutions. Bold and italics font indicates the best solution for each processing strategy [PPP (italics) and DD (bold)]. It can be seen that the best solution (the highest correlation and the lowest standard error) in both is where VMF1 and the same formula to estimate the $T_{\mathrm{m}}$ values (Bevis) were used.

\section{Discussion and summary}

In this study, the correlation between IWV and atmospheric opacity are presented, as well as the linear regression coefficients between them. To estimate ZWD, which were converted to IWV, two GNSS processing strategies were used (PPP and DD) with two mapping functions (VMF and GMF). The calculated IWV was compared to the atmospheric opacity derived from the sky-dip method performed by the $32 \mathrm{~m}$ radio telescope located in Piwnice/Torun (Poland). The water vapor weighted mean temperature is necessary for both the conversion of ZWD to IWV and for the $\tau_{0}$ estimation. For this purpose, we used two different methods: the Bevis method (Bevis et al. 1992), which is based on a linear regression between surface temperature and weighted mean temperature, and the Maddalena method (Maddalena and Johnson 2005), which also based on a linear regression, but accounting for the dependency on the frequency of the signal.

Based on our analysis, it can be stated that there is a high correlation between the IWV and the $\tau_{0}$ values, which confirm previous studies (Deuber et al. 2005). However, it is worth noting that the correlation depends on the processing strategies. The highest value $(0.9573)$ was obtained for the PPP with the VMF1 and $T_{\mathrm{m}}$ calculated from the Bevis formula (9). A similar value, although lower (0.9568), was obtained for DD with the same parameters as for PPP. It should be noted that this DD solution is characterized by the lowest standard error. Interestingly, when that GMF was used, the solution with the highest correlation and lowest standard error was obtained for PPP. In case of VMF1, the preferred processing strategy was DD. For all the VMF1 solutions, the correlations were higher than for the respective GMF solutions. This is probably caused by the fact that VMF1 is determined on the basis of an operational numerical weather model and better represents the real conditions of the troposphere. Regardless of the mapping function used, it should be stated that the linear regression coefficients are strongly depended on the used processing strategy. In both the VMF1 and GMF solutions, differences between coefficients $a$ and $b$ can be noticed. Using VMF1, these differences are slightly smaller.

We investigated two water vapor weighted mean temperature models and their impact on IWV, $\tau_{0}$, and the correlation between them. Based on the results presented, it can be stated that there is no significant difference between $T_{\mathrm{m}}$ estimated using the Bevis or Maddalena (for $22 \mathrm{GHz}$ frequency) methods. A high bias of $-12.8 \mathrm{~K}$, in comparison with the data from radio soundings, can be observed if $T_{\mathrm{m}}$ is calculated using the Maddalena method for GNSS frequencies (Fig. 3). Such a bias has a significant impact on the IWV, where its value amounted to $-1.15 \mathrm{~mm}$. Such a high bias eliminated the $T_{\mathrm{m}}$ calculated using the Maddalena method from the ZWD to IWV conversion process. We decided to show the mixed results. Based on the results presented, it can be seen that a high correlation was obtained, which was only slightly lower than when the same $T_{\mathrm{m}}$ was used. Larger standard errors were obtained, but the differences between them and the other results were on the same level as the difference between PPP and DD processing strategies.

Based on the studies conducted, it can be stated that IWV derived from GNSS observations may be used to, e.g., calibrate archived observations from radio telescopes or as a verification of obtained $\tau_{0}$ values. Moreover, when the IWV is estimated in real-time mode, it can be used as a primary source of calibration data, instead of the microwave radiometer or the sky-dip method for the atmospheric opacity measurements. On the other hand, if we have the $\tau_{0}$ values, they can be a valuable verification of IWV derived from GNSS processing. The coefficients of the linear regression presented in this study confirm that both PPP and DD processing strategy can be applied for above applications. 
Acknowledgements The authors would like to thank the TPI Poland company (www.tpi.com.pl) for providing observation data from the TPI NETpro network. This research was partly financed by the Faculty of Civil and Environmental Engineering of Gdansk University of Technology statutory research funds. Calculations were carried out at the Academic Computer Centre in Gdansk. We are also grateful to anonymous reviewers for providing their insights.

Open Access This article is distributed under the terms of the Creative Commons Attribution 4.0 International License (http://creativecommons.org/licenses/by/4.0/), which permits unrestricted use, distribution, and reproduction in any medium, provided you give appropriate credit to the original author(s) and the source, provide a link to the Creative Commons license, and indicate if changes were made.

\section{References}

Ahmed F, Václavovic P, Teferle FN, Douša J, Bingley R, Laurichesse D (2016) Comparative analysis of real-time precise point positioning zenith total delay estimates. GPS Solut 20(2):187-199. https://doi. org/10.1007/s10291-014-0427-Z

Altamimi Z, Rebischung P, Metivier L, Xavier C (2016) ITRF2014: a new release of the International Terrestrial Reference Frame modeling nonlinear station motions. J Geophys Res Solid Earth 121(8):6109-6131. https://doi.org/10.1002/2016JB013098

Askne J, Nordius H (1987) Estimation of tropospheric delay for microwaves from surface weather data. Radio Sci 22(3):379-386. https://doi.org/10.1029/RS022i003p00379

Baldysz Z, Nykiel G, Araszkiewicz A, Figurski M, Szafranek K (2016) Comparison of GPS tropospheric delays derived from two consecutive EPN reprocessing campaigns from the point of view of climate monitoring. Atmos Meas Tech 9(9):4861-4877. https:// doi.org/10.5194/amt-9-4861-2016

Bergeot N, Chevalier JM, Bruyninx C, Pottiaux E, Aerts W, Baire Q, Legrand J, Defraigne P, Huang W (2014) Near real-time ionospheric monitoring over Europe at the royal observatory of Belgium using GNSS data. J Space Weather Space Clim 4:A31. https://doi.org/10.1051/swsc/2014028

Bevis M, Businger S, Herring TA, Rocken C, Anthes RA, Ware RH (1992) GPS meteorology: remote sensing of atmospheric water vapor using the global positioning system. J Geophys Res 97(D14):15787-15801. https://doi.org/10.1029/92JD01517

Boehm J, Werl B, Schuh H (2006a) Troposphere mapping functions for GPS and very long baseline interferometry from European centre for medium-range weather forecasts operational analysis data. $\mathrm{J}$ Geophys Res. https://doi.org/10.1029/2005JB003629

Boehm J, Niell AE, Tregoning P, Schuh H (2006b) Global mapping function (GMF). A new empirical mapping function based on numerical weather model data. Geophys Res Lett 33:L07304-1L07304-4. https://doi.org/10.1029/2005GL025546

Chen G, Herring A (1997) Effects of atmospheric azimuthal asymmetry on the analysis of space geodetic data. J Geophys Res 102(B9):20489-20502. https://doi.org/10.1029/97JB01739

Dach R, Lutz S, Walser P, Fridez P (Eds) (2015) Bernese GNSS software version 5.2. User manual, Astronomical Institute, University of Bern, Bern Open Publishing. ISBN:978-3-906813-05-9. https:// doi.org/10.7892/boris.72297

Davis JL, Herring TA, Shapiro LI, Rogers AEE, Elgered G (1985) Geodesy by radio interferometry: effects of atmospheric modeling errors on estimates of baseline length. Radio Sci 20(6):1593-1607

Deuber B, Morland J, Martin L, Kampfer N (2005) Deriving the tropospheric integrated water vapor from tipping curve-derived opacity near $22 \mathrm{GHz}$. Radio Sci 40:RS5011. https://doi. org/10.1029/2004RS003233

Dow JM, Neilan RE, Rizos C (2009) The international GNSS service in a changing landscape of global navigation satellite systems. J Geod 83(3):191-198. https://doi.org/10.1007/s00190-008-0300-3

Figurski M, Araszkiewicz A, Szafranek K, Nykiel G, Podkowa A (2015) CGSREFMON 2.0 — coordinates stability monitoring system of the polish GNSS reference stations. In: Conference: 15 th international multidisciplinary scientific GeoConference SGEM 2015, vol 2. https://doi.org/10.5593/SGEM2015/B22/S9.018

Guerova G, Jones J, Douša J, Dick G, de Haan S, Pottiaux E, Bock O, Pacione R, Elgered G, Vedel H, Bender M (2016) Review of the state of the art and future prospects of the ground-based GNSS meteorology in Europe. Atmos Meas Tech 9:5385-5406. https://doi.org/10.5194/amt-9-5385-2016

Hernández-Pajares M, Juan JM, Sanz J, Orus R, Garcia-Rigo A, Feltens J, Komjathy A, Schaer SC, Krankowski A (2009) The IGS VTEC maps: a reliable source of ionospheric information since 1998. J Geod 83(3):263-275. https://doi.org/10.1007/ s00190-008-0266-1

Li X, Dick G, Lu C, Ge M, Nilsson T, Ning T, Wickert J, Schuh H (2015) Multi-GNSS meteorology: real-time retrieving of atmospheric water vapor from BeiDou, Galileo, GLONASS, and GPS observations. IEEE Trans Geosci Remote Sens. https:// doi.org/10.1109/TGRS.2015.2438395

Maddalena RJ, Johnson CH (2005) High precision calibration of data from single-dish radio telescopes. In: American astronomical society meeting 207, id.173.02; Bull Am Astron Soc, vol 37, p 1438

Marvil J (2010) EVLA Memo 143: improving the frequency resolution of the default atmospheric opacity model. In: National radio astronomy observatory

Mendes VB (2000) Modeling the neutral-atmospheric propagation delay in radiometric space techniques. In: UNB geodesy and geomatics engineering technical report, no. 199. http://www2. unb.ca/gge/Pubs/TR199.pdf

Nilsson T, Elgered G (2008) Long-term trends in the atmospheric water vapor content estimated from ground-based GPS data. J Geophys Res. https://doi.org/10.1029/2008JD010110

Nykiel G, Zanimonskiy YM, Yampolski YM, Figurski M (2017) Efficient usage of dense GNSS networks in central europe for the visualization and investigation of ionospheric TEC variations. Sensors 17(10):2298. https://doi.org/10.3390/s17102298

Saastamoinen J. (1972) Atmospheric correction for the troposphere and stratosphere in ranging satellites. In: The use of artificial satellites for geodesy, geophysical monography no. 15, American Geophysical Union, pp 247-251

Schuler T (2001) On ground-based GPS tropospheric delay estimation. Doctor's thesis, Studiengang Geodäsie und Geoinformation, Universität der Bundeswehr München, Germany, vol 73, Neubiberg

Solbrig P (2000) Untersuchungen über die Nutzung numerischer Wettermodelle zur Wasserdampfbestimmung mit Hilfe des Global Positioning Systems. Diploma thesis, Institute of Geodesy and Navigation, University FAF Munich, Germany

Song DS, Grejner-Brzezinska DA (2009) Remote sensing of atmospheric water variation from GPS measurements during a severe weather event. Earth Planets Space 61:1117-1125. https://doi. org/10.1186/BF03352964

Steigenberger P, Boehm J, Tesmer V (2009) Comparison of GMF/ GPT with VMF1/ECMWF and implications for atmospheric loading. J Geod 83:943. https://doi.org/10.1007/ s00190-009-0311-8

Suresh Raju C, Saha K, Thampi BV, Parameswaran K (2007) Empirical model for mean temperature for Indian zone and estimation of 
precipitable water vapor from ground based GPS measurements. Ann Geophys 25:1935-1948

Van Malderen R, Brenot H, Pottiaux E, Beirle S, Hermans C, De Mazière M, Wagner T, De Backer H, Bruyninx C (2014) A multisite intercomparison of integrated water vapour observations for climate change analysis. Atmos Meas Tech 7:2487-2512. https:// doi.org/10.5194/amt-7-2487-2014

White SM, Zauderer BA (2009) Single dish aperture efficiency measurements at CARMA, CARMA Memorandum Series \#49, March 13

Wijaya DD, Böhm J, Karbon M, Krásná H, Schuh H (2013) Atmospheric pressure loading. In: Böhm J, Schuh H (eds) Atmospheric effects in space geodesy. Springer, Berlin, pp 137-157. https://doi. org/10.1007/978-3-642-36932-2_4

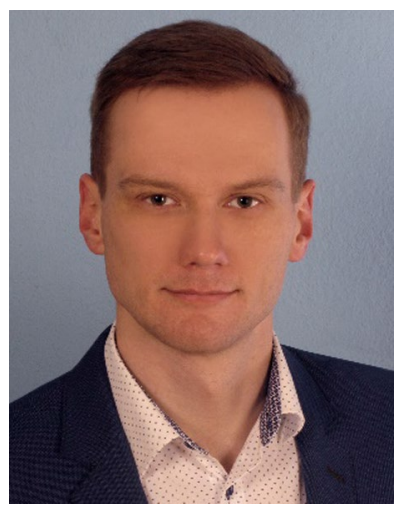

Grzegorz Nykiel is an Assistant Professor at the Faculty of Civil and Environmental Engineering of the Gdansk University of Technology (GUT) in Poland. In 2016, he obtained his Ph.D. with the doctoral thesis "Methodology of absolute positioning using GPS and Galileo phase observations". His research interests cover satellite navigation, algorithms for precise multi-GNSS positioning, GNSSbased troposphere and ionosphere study, and also numerical weather prediction models.

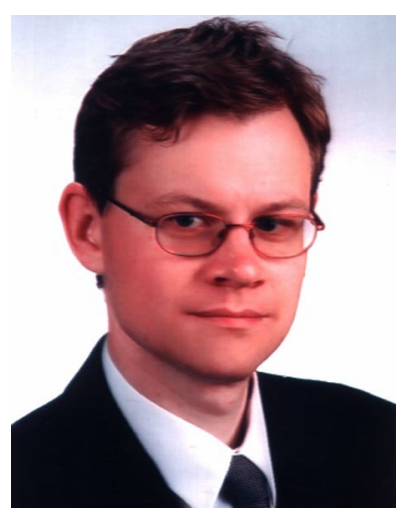

Pawel Wolak works at the Department of Radio Astronomy of the Centre for Astronomy, Faculty of Physics, Astronomy and Informatics, Nicolaus Copernicus University in Torun, Poland. He obtained the Ph.D. in 2014 with the doctoral thesis "Polarization properties of $\mathrm{OH}$ masers in late-type stars". His research interests cover astrophysical masers associated with young stellar objects and evolved stars. He is using the $32 \mathrm{~m}$ dish of NCU as well as the European VLBI Network to study the maser variability and morphology.

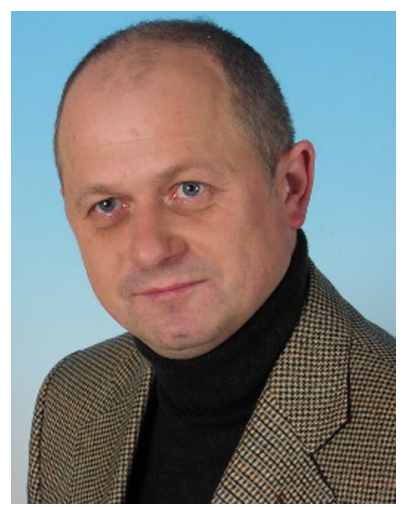

Prof. Mariusz Figurski is a Professor at the Faculty of Civil and Environmental Engineering of the Gdansk University of Technology. He earned his Ph.D. in Geodesy and Cartography in 1995 and habilitation in 2005. He was responsible for establishing geodetic control networks in Poland (WSSG, POLREF, EUREF-POL, EUVN) by means of GNSS technique. For his scientific achievements, he was awarded by Polish President with Silver (in 2007) and Gold Cross of Merit (in 2014). His research interests cover reference frames realization in global, regional and local scale, satellite navigation, GNSS precise positioning, geodynamics, numerical weather prediction models with data assimilation, and also GNSS-based ionosphere and troposphere study. 